\title{
Design, Synthesis and Antidiabetic, Cardiomyopathy Studies of Cinnamic Acid-Amino Acid Hybrid Analogs
}

\section{S Prakash ${ }^{1}$, D Maji $^{2 *}$, S Samanta ${ }^{2}$ and RK Sinha ${ }^{3}$}

${ }^{1}$ RAM-EESH Institute of Vocational and Technical Education, Greater, Noida, India

${ }^{2}$ Department of Pharmaceutical Sciences, Birla Institute of Technology, Mesra, Ranchi-835215, India

${ }^{3}$ Department of Biomedical Instrumentation, Birla Institute of Technology, Mesra, Ranchi-835215, India

\begin{abstract}
Diabetes mellitus is a chronic metabolism disorder characterized by hyperglycemia due to insulin deficiency or insulin resistance. Associated complications include Myocardial infarction, cardiomyopathy, retinopathy, neuropathy, nephropathy, etc.

Cinnamic acid analogs (SSPCO-SSPC20) containing different amino acids were designed and docked into crystal structure of AMPK and PPARs. Among the 20 designed compounds five compounds namely SSPC5, SSPC8, SSPC11, SSPC14, SSPC15 showed good docking scores using Glide 5.0 Maestro program and were subjected to ADME prediction by using software Quickprop version 3.1. These were then selected for synthesis, characterized and antidiabetic activity carried out using Alloxan induced diabetic rat model by measuring blood glucose levels using glucometer at $0,1,2,4,6,8$ and 24 hrs through the tail vein puncture method. SSPC5, SSPC8, SSPC11, SSPC14 showed $\%$ reduction in blood glucose of $23.02 \%, 37.02 \%, 14.04 \%$ and $15.96 \%$ as compared to standard with $33.53 \%$ reduction.

As SSPC14 had good and comparable docking scores in both AMPK and PPAR y receptor, so it was subjected for the Diabetic as well as diabetic cardiomyopathy activity by recording the electrocardiogram of both diabetic and control rat. It was found to be very efficient at low dose and had a prolong duration of action on the heart (Up to 54 hrs). Thus this study indicated that such hybrid antidiabetic drug with dual action on hyperglycemia and cardiac function is desirable and cost effective.
\end{abstract}

Keywords: Cinnamic acid analogues; Amino acid; Designing; antidiabetics; Diabetic cardiomyopathy; ADME profile

\section{Introduction}

The epidemic of obesity and sedentary lifestyle is projected to result in over 300 million people with diabetes mellitus by 2025 [1].

Diabetes Mellitus is a syndrome of disordered metabolism usually due to a combination of hereditary and environmental causes resulting in hyperglycemia (fasting plasma glucose $>7.0 \mathrm{mmol} / \mathrm{lit}\left(126 \mathrm{mg} \mathrm{dl}^{-1}\right)$ or plasma glucose $>10 \mathrm{mmol} / \mathrm{lit}$, two hours after a meal) due to insulin deficiency and/or insulin resistance [2].

Diabetes is associated with a number of complications both microvascular and macrovascular. Microvascular complications include diabetic nephropathy, neuropathy, and retinopathy. Macrovascular complication includes coronary artery disease, peripheral arterial disease, and stroke.

Diabetic Cardiomyopathy is responsible for $80 \%$ of deaths among diabetic patients much of which has been attributed to CAD (coronary artery disease). This was first described in 1972 on the basis of observations in four diabetic patients who presented with HF (heart failure) without evidence of hypertension, CAD, valvular or congenital heart disease [3].

Diabetic cardiomyopathy refers to a disease process which affects the myocardium in diabetic patients causing a wide range of structural abnormalities eventually leading to LVH [left ventricular (LV) hypertrophy] and diastolic and systolic dysfunction or a combination of these [4] (Figure 1).

The treatments for diabetic cardiomyopathy include Glycemic control, $\beta$-blockers, ACE Inhibitors, Angiotesin II receptor antagonists, $\mathrm{Ca} 2+$ channel blockers, Statins and Thiazolidinediones [5].
Cinnamic acid and its derivatives have been reported to show various pharmacological activities like hepatoprotective action [6], antidiabetics action [7], antioxidant action [8], etc. Also cinnamic acid is known to have good cardioprotective activity [9]. Earlier works have

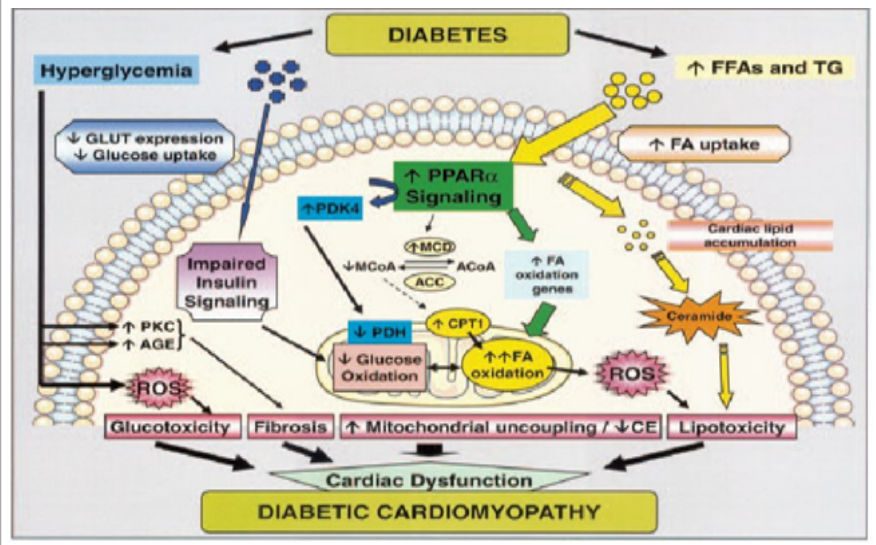

Figure 1: Co-relation between Diabetes and Cardiomyopathy [5].

*Corresponding author: Deepanwita Maji, Department of Pharmaceutical Sciences, Birla Institute of Technology, Mesra, Ranchi-835215, India, Tel: +919334870271; Fax: 0651-2276247; E-mail: deepanwita.maji@gmail.com

Received November 16, 2013; Accepted February 25, 2014; Published February 27, 2014

Citation: Prakash S, Maji D, Samanta S, Sinha RK (2014) Design, Synthesis and Antidiabetic, Cardiomyopathy Studies of Cinnamic Acid-Amino Acid Hybrid Analogs. Med chem 4: 345-350. doi:10.4172/2161-0444.1000163

Copyright: (c) 2014 Prakash S, et al. This is an open-access article distributed under the terms of the Creative Commons Attribution License, which permits unrestricted use, distribution, and reproduction in any medium, provided the original author and source are credited. 
shown peptides to have significant antidiabetics activity like Exenatide, which is an incretin mimetic [10]. Studies showed that a hexapeptide (Gly-Ala-Gly-Val-Gly-Tyr) had improved glucose transport and also exerts beneficial lipid metabolic effects [11]. Because of this a series of cinnamic acid-amino-acid hybrid series were designed, docked using Glide 5.0 and the best docked five compounds were synthesized. Antidiabetic activity of the five compounds was done on alloxanised rats and a new non-invasive animal model was developed to study the diabetic cardiomyopathy.

\section{Material and Methods}

\section{Chemistry}

Synthesis was carried out in Mini Block XT-Parallel Synthesizer (Mettler Toledo). TLC was done using (BAW) n- butanol: glacial acetic acid and water 4:1:1 solvent system and further characterized by melting point using Optimelt (Stanford Research System), FTIR using (FTIR-8400S, SHIMADZU), 1H NMR was done and data Collected on Wormhole-vnmrs 400 and Mass spectroscopy was also done.

\section{Designing}

Cinnamic acid -amino acid hybrid compounds containing different amino acid combinations of Alanine, Valine, Glycine, Leucine, Isoleucin, Proline, Phenylalanine, Cysteine, Methonine, Aspartic acid, Glutamic acid., Glutamine, Threonine, Asparagine, Serine, Lysine, Arginine, Histidine and Tyrosine were designed using Schrodinger, (LLC New York, 2008). Schrodinger's computational programs: Maestro's, MacroModel, LigPrep and Glide5.0. The designed compounds were docked into crystal structure of AMPK (PDB IDs: 2Y94) and PPARs (PDB IDs: 3ET0, 3ET1 and 3ET2). ADME properties (Table 2) of designed compounds were found out by using software Qikprop version 3.1 (Figures 2 and 3).

\section{Synthesis}

Cinnamic acid-amino acid hybrid compounds SSPC5, SSPC8, SSPC11, SSPC14 and SSPC15 were synthesized using Liquid phase peptide synthesis method. Cinnamic acid was prepared using benzaldehyde and acetic anhydride.

\section{Biological evaluation}

The antidiabetic activity of the synthesized test drugs was carried out on Alloxan induced diabetic rats by measuring the decrease in blood glucose level by ANOVA followed by Dunnett's $t$-test with equal sample size. Diabetic cardiomyopathy activity was obtained by recording the electrocardiogram of both diabetic and control rat.

\section{Experimental Section}

\section{Docking studies}

The 20 designed compounds were docked into crystal structure of AMPK (PDB IDs: 2Y94) and PPARs (PDB IDs: 3ET0, 3ET1 and 3ET2) which is the most accurate structure available. The interaction energy between designed molecule and receptors were calculated and the results are presented in the Table 1 . The score represented in terms of Gibbs free energy $(\Delta G)$. ADME properties of designed compounds were found out by using software Qikprop version 3.1.

* QP $\log$ Po/w: Predicted octanol /water partition coefficient; Range, -2.0 to 6.5

* QP $\log$ S: Predicted aqueous solubility, $\log$ S. S in moles/liter is the concentration of the solute in a saturated solution that is in equilibrium with the crystalline solid,log S; Range, -6.5 to 0.5

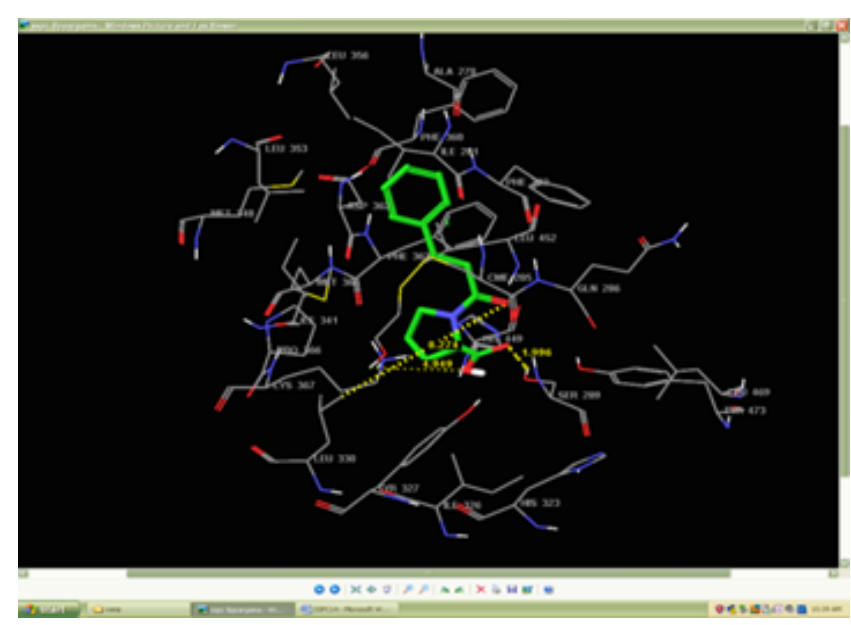

Figure 2: Docking of SSPC8 IN PPAR Y.

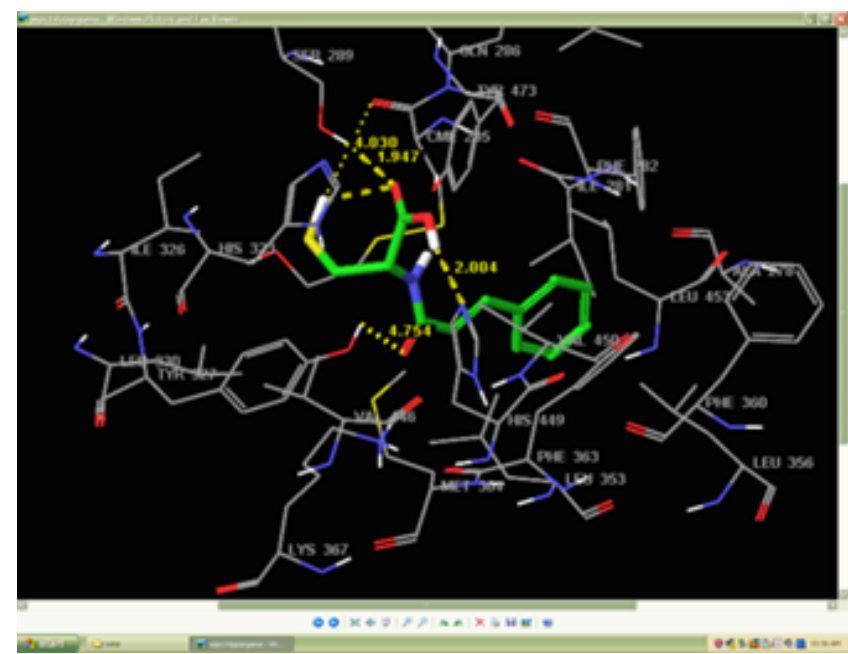

Figure 3: Docking of SSPC14 IN PPAR Y.

\begin{tabular}{|c|c|c|c|c|c|}
\hline $\begin{array}{c}\text { LIGAND } \\
\text { NAME }\end{array}$ & COMPOSITION & $\begin{array}{c}\text { DOCKING } \\
\text { SCORE(In-AMPK) }\end{array}$ & PPARY & PPARa & PPARठ \\
\hline SSPC0 & Cinnamic acid & -11.67 & -4.79 & -4.45 & -5.12 \\
\hline SSPC1 & Cinn-Ala & -12.40 & -6.35 & -6.128 & -7.23 \\
\hline SSPC2 & Cinn -val & -7.91 & -7.85 & -8.34 & -3.80 \\
\hline SSPC3 & Cinn -Leu & -7.91 & -5.60 & -7.78 & -6.44 \\
\hline SSPC4 & Cinn -lle & -8.98 & -5.57 & -3.90 & -1.33 \\
\hline SSPC5 & Cinn -Phe & -12.89 & -8.47 & -6.64 & -7.35 \\
\hline SSPC6 & Cinn -Try & -10.13 & -7.83 & -8.25 & -6.44 \\
\hline SSPC7 & Cinn -Met & -10.04 & -6.87 & -8.69 & -7.49 \\
\hline SSPC8 & Cinn -Pro & -10.08 & -10.08 & -8.64 & -4.06 \\
\hline SSPC9 & Cinn -Asp & -11.62 & -6.56 & -3.88 & -6.86 \\
\hline SSPC10 & Cinn -Glu & -11.63 & -6.60 & -4.12 & -1.93 \\
\hline SSPC11 & Cinn -Gly & -12.47 & -6.29 & -5.103 & -4.23 \\
\hline SSPC12 & Cinn -Ser & -10.19 & -6.85 & -7.09 & -6.52 \\
\hline SSPC13 & Cinn -Thr & -9.72 & -6.24 & -6.68 & -5.40 \\
\hline SSPC14* & Cinn-Cys & -8.66 & -8.39 & -7.20 & -7.03 \\
\hline SSPC15 & Cinn -Tyr & -12.37 & -7.09 & -9.97 & -6.53 \\
\hline SSPC16 & Cinn -Asn & -9.65 & -7.96 & -4.27 & -5.00 \\
\hline SSPC17 & Cinn -GIn & -8042 & -7.05 & -4.43 & -8.30 \\
\hline SSPC18 & Cinn -Lys & -10.34 & -5.95 & -4.55 & -4.56 \\
\hline SSPC19 & Cinn -Arg & -11.10 & -4.77 & -3.90 & -2.94 \\
\hline SSPC20 & Cinn -His & -11.96 & -6.87 & -7.36 & -8.36 \\
\hline Table 1: D & CKING SCORE & & & \\
\hline
\end{tabular}

Table 1: DOCKING SCORE of docked Cinnamic acid-amino acid hybrid analogs. 
* Human Oral Absorption: Qualitative; $1 \rightarrow$ Low, $2 \rightarrow$ Medium, $3 \rightarrow$ High

* Percent Human Oral absorption: 0 to $100 \%$ scale; [ $>80 \% \rightarrow$ High, $<20 \% \rightarrow$ Poor.

* SSPC14 was selected for both antidiabetic and diabetic cardiomyopathic studies.

\section{Synthesis}

In a dry $250 \mathrm{ml}$ round-bottomed flask fitted with an air condenser carrying a calcium chloride guard-tube, $21 \mathrm{~g}(20 \mathrm{ml}, 0.2 \mathrm{~mol})$ of pure Benzaldehyde, $30 \mathrm{~g}(28 \mathrm{ml}, 0.29 \mathrm{~mol})$ of acetic anhydride and $12 \mathrm{~g}$ $(0.122 \mathrm{~mol})$ of freshly fused and finely powdered potassium acetate were added (Scheme 1). The mixture was heated on a sand bath at $160^{\circ} \mathrm{C}$ for 1 hour and at $170-180^{\circ} \mathrm{C}$ for 3 hours, poured while still hot $\left(80-100^{\circ} \mathrm{C}\right)$ into about $100 \mathrm{ml}$ of water contained in an 1 liter roundbottomed flask which has previously been fitted for steam distillation. A saturated aqueous solution of sodium carbonate was added with vigorous shaking until a drop of the liquid withdrawn on the end of a glass rod turns red litmus a distinct blue. The solution was steam distilled until all the unchanged benzaldehyde was removed and the distillate was clear. The residual solution was cooled and filtered from resinous by-products. The filtrate was acidified by adding concentrated hydrochloric acid slowly, with vigorous stirring until the evolution of carbon dioxide ceases. Cinnamic acid was recrystallized from a mixture of 3 volumes of water and 1 volume of rectified spirit. The yield of dry Cinnamic acid (colorless crystals), m.p. $133^{\circ} \mathrm{C}$, is $18 \mathrm{~g}(62 \%)$.

\section{General procedure for the synthesis of hybrid compounds} SSPC5, SSPC8, SSPC11, SSPC14, and SSPC15

Equimolar quantity of Cinnamic acid and amino acid were coupled using $10 \mathrm{ml}$ of $\mathrm{CPE}$ reagent stirred till clear at a temp of $0-5^{\circ} \mathrm{C}$ $(0.01 \mathrm{~mol})$. To this mixture, triethylamine was added till the $\mathrm{pH} 7$ as mentioned keeping the reaction (Scheme 2) temperature kept below $5^{\circ} \mathrm{C}$ and kept $6 \mathrm{hrs}$ at $0^{\circ} \mathrm{C}$. The product so obtained was filtered out and washed with solvent ether and dried., recrystallized using ethanol.

\begin{tabular}{|c|c|c|c|c|c|}
\hline Compound & $\begin{array}{c}\text { Molecular } \\
\text { weight }\end{array}$ & QPlogPo/w & QPlogS & $\begin{array}{c}\text { Human oral } \\
\text { absorption }\end{array}$ & $\begin{array}{c}\text { \%Oral } \\
\text { absorption }\end{array}$ \\
\hline SSPC5 & 295.3 & 3.742 & -3.793 & 3 & 85.43 \\
\hline SSPC8 & 263.2 & 2.460 & -3.188 & 3 & 81.14 \\
\hline SSPC11 & 235.2 & 1.807 & -2.333 & 3 & 69.57 \\
\hline SSPC14 & 311.2 & 2.885 & -2.939 & 3 & 78.70 \\
\hline SSPC15 & 262.2 & 2.989 & -2.436 & 2 & 71.38 \\
\hline
\end{tabular}

Table 2: Predicted ADME properties of the five best docked hybrid compounds.

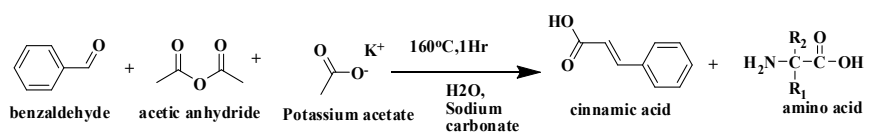

Scheme 1: Synthesis of Cinnamic Acid.

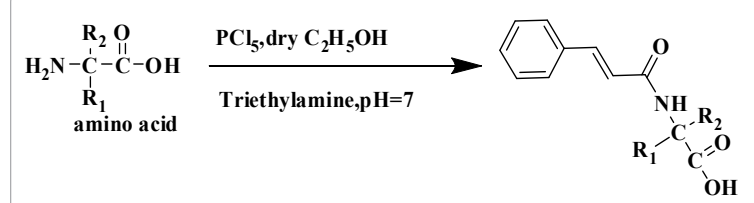

R1=R2=H, alkyl,benzyl

Cinnamic acid-amino acid Hybrid

Scheme 2: Synthesis of Cinnamic Acid-Amino acid hybrid.
TLC was using solvent system of n- Butanol: Glacial Acetic Acid: Water=4:1:1.Futher characterization was done using melting point using Optimelt (Stanford Research System), FTIR using (FTIR-8400S, SHIMADZU), 1H NMR was done and data Collected on Wormholevnmrs 400.and Mass spectroscopy was also done.

SSPC5 (Cinnamic acid-Phenylalanine) was obtained by recrystallization from ethanol as white crystalline solid $(2.02 \mathrm{~g}$, 82.44\%). IR (KBr, $\left.v, \mathrm{~cm}^{-1}\right): 3450.77\left(v_{\mathrm{N}-\mathrm{H}}\right), 2966.02\left(v_{\mathrm{C}-\mathrm{H}}\right), 2673.43$ $\left(v_{\mathrm{O}-\mathrm{H}}\right), 1925.02\left(v_{\mathrm{C}=\mathrm{O}}\right), 1739.85\left(v_{\mathrm{C}=\mathrm{O}}\right) 1475.59\left(v_{\mathrm{C}-\mathrm{H}} \mathrm{def}\right), 1176.62$ $\left(v_{\mathrm{C}-\mathrm{N}}\right) ;{ }^{1} \mathrm{HNMR}(300 \mathrm{~Hz}, \delta \mathrm{ppm}, \mathrm{D} 2 \mathrm{O}): 7.5(\mathrm{~m}, 6 \mathrm{H}), 3.12(\mathrm{~d}, 2 \mathrm{H}) . \mathrm{m} / \mathrm{z}$ : 297(M+2), $295(\mathrm{M}), 294(\mathrm{M}-\mathrm{H})$.

SSPC8 (Cinnamic acid-Proline) was obtained by recrystallization from ethanol as white crystals $(2.02 \mathrm{~g}, 82.44 \%)$. IR $\left(\mathrm{KBr}, v, \mathrm{~cm}^{-1}\right): 3412$ $\left(v\right.$ N-H str of amide), $2966.02\left(v_{\mathrm{C}-\mathrm{H}}\right), 2671.50\left(v_{\mathrm{O}-\mathrm{H}}\right), 1925.02\left(v_{\mathrm{C}=\mathrm{O}}\right)$, $1613.83\left(v_{\mathrm{C}=\mathrm{O}}\right), 1475.59\left(v_{\mathrm{C}-\mathrm{H}} \mathrm{def}\right), 1176.02\left(v_{\mathrm{C}-\mathrm{N}} \mathrm{str}\right)$

${ }^{1} \mathrm{H}$ NMR $(300 \mathrm{~Hz}, \delta$ ppm, D2O), 7.5 (m, 6H) $4.23(\mathrm{t}, \mathrm{J}=2 \mathrm{H}) 3.457$ (d, $\mathrm{J}=7.2 \mathrm{~Hz}, 1 \mathrm{H})$. The $\mathrm{m} / . \mathrm{z}$. shows principal fragment ions at $\mathrm{m} / \mathrm{z} 245(\mathrm{M})$, 244(M - H), 229 (M - OH).

SSPC11 (Cinnamic acid-Glycine) was obtained by recrystallization from ethanol as white crystals $(1.75 \mathrm{~g}, 85.36 \%)$. IR $\left(\mathrm{KBr}, v, \mathrm{~cm}^{-1}\right): 3412$ $\left(v_{\mathrm{N}-\mathrm{H}}\right), 2966.62\left(v_{\mathrm{C}-\mathrm{H}}\right), 2615.56\left(v_{\mathrm{O}-\mathrm{H}}\right), 1925.02 \mathrm{~cm}^{-1}\left(v_{\mathrm{C}=\mathrm{O}} 1613.83 \mathrm{~cm}^{-1}\right.$ $\left(v_{\mathrm{C}=\mathrm{O}}\right), 1475.59 \mathrm{~cm}^{-1}\left(v_{\mathrm{C}-\mathrm{H}}\right), 1176.62 \mathrm{~cm}^{-1}\left(v_{\mathrm{C}-\mathrm{N}} \mathrm{str}\right)$;

${ }^{1} \mathrm{HNMR}\left(300 \mathrm{~Hz}, \delta \mathrm{ppm}, \mathrm{D}_{2} \mathrm{O}\right) 7.6(\mathrm{~m}, 6 \mathrm{H}), 4.247$ (s, 1H, ) 3.92(s, $1 \mathrm{H})$. The $\mathrm{m} / . \mathrm{z}$. shows principal fragment ions at $\mathrm{m} / \mathrm{z} 205(\mathrm{M}), 204(\mathrm{M}$ $\mathrm{H}), 188(\mathrm{M}-\mathrm{OH})$.

SSPC14 (Cinnamic acid-Cysteine) was obtained by recrystallization from ethanol as white crystal. IR $\left(\mathrm{KBr}, v, \mathrm{~cm}^{-1}\right): 3412$ $\left(v_{\mathrm{N}-\mathrm{H}}\right), 2970.48\left(v_{\mathrm{C}-\mathrm{H}}\right), 2673.43 \mathrm{~cm}^{-1}\left(v_{\mathrm{O}-\mathrm{H}}\right), 1925.03\left(v_{\mathrm{C}=\mathrm{O}}\right), 1637.02$ $\left(v_{\mathrm{C}=\mathrm{O}}\right) 1475.59 \mathrm{~cm}^{-1}\left(v_{\mathrm{C}-\mathrm{H}}\right), 1176.02 \mathrm{~cm}^{-1}\left(v_{\mathrm{C}-\mathrm{N}}\right) ;{ }^{1} \mathrm{H}$ NMR $(300 \mathrm{~Hz}$, Sppm, $\left.\mathrm{D}_{2} \mathrm{O}\right) 7.60(\mathrm{~m}, 6 \mathrm{H}), 6.46(\mathrm{~d}, 1 \mathrm{H}), 2.997(\mathrm{~d}, \mathrm{~J}=7.5,2 \mathrm{H}) . \mathrm{m} / \mathrm{z} 205$ ( $\left.\mathrm{M}-\mathrm{CH}_{2} \mathrm{SH}\right), 211(\mathrm{M}-\mathrm{COOH})$.

SSPC15 (Cinnamic acid-Tyrosine) was obtained by recrystallization from ethanol as white crystals $(2.12 \mathrm{~g}, 80.00 \%)$, IR $\left(\mathrm{KBr}, v, \mathrm{~cm}^{-1}\right): 3450.77\left(v_{\mathrm{N}-\mathrm{H}}\right), 2966.62\left(v_{\mathrm{C}-\mathrm{H}}\right), 2675.36\left(v_{\mathrm{O}-\mathrm{H}}\right), 1925.02$ $\left(v_{\mathrm{C}=\mathrm{O}}\right), 1739.85\left(v_{\mathrm{C}=\mathrm{O}}\right) 1475.59\left(v_{\mathrm{C}-\mathrm{H}}\right), 1176.02\left(v_{\mathrm{C}-\mathrm{N}}\right) ;{ }^{1} \mathrm{HNMR}(300 \mathrm{~Hz}$, Sppm, $\left.\mathrm{D}_{2} \mathrm{O}\right) 7.6(\mathrm{~m}, 6 \mathrm{H}), 4.247(\mathrm{~s}, 1 \mathrm{H}) ,3.92(\mathrm{~s}, 1 \mathrm{H}) . \mathrm{m} / \mathrm{z} 205(\mathrm{M}), 204$ $(\mathrm{M}-\mathrm{H}), 188(\mathrm{M}-\mathrm{OH})$.

\section{Anti-diabetic activity}

The antidiabetic activity of the synthesized test drugs were carried out on Alloxan induced diabetic rats and measuring the decrease in blood glucose level. Male albino rats of Wistar strain weighing about 145-240gm were used. Animals were maintained at $22 \pm 2^{\circ} \mathrm{C}$ with 12 hr. light: $12 \mathrm{hr}$. dark cycle. Each experimental group consisting of 4 animals each. Diabetes was induced in groups II to IX as shown in Table 3 below by injecting freshly prepared alloxan (dissolved in $0.9 \%$ $\mathrm{NaCl}$ injectable solution to produce a concentration of $40 \mathrm{mg} / \mathrm{mL}$ ) intraperitonealy at a dose of $40 \mathrm{mg} / \mathrm{kg}$ to overnight fasting animals. Rats were then tested for sufficient levels of hyperglycemia two days after injection and 4 weeks post-injection.

\section{Cardiomyopathy studies}

The Cardiomyopathy study of the synthesized test drug SSPC14 had been studied as it showed comparative docking scores on both PPAR $\gamma$ and AMPK enzyme, in the Alloxan induced diabetic rats, which produced cardiomyopathy symptoms after 14 days of Alloxan treatment. Rats were tested for sufficient levels of cardiomyopathy 
using Echocardiography 7, 14 days after injection and 4 weeks postinjection. A new non-invasive method of detecting Electrocardiogram was designed and the software used for carrying out the ECG of rats was Biopac Student Lab and the analysis and power spectrum analysis was done by using Acknowledge 4 .

* Values are expressed as mean \pm S.E.M.; $\mathrm{n}=4$;

* Pharmacological data were analyzed by one-way analysis of variance (ANOVA) followed by Dunnett's $t$ test with equal sample size. ${ }^{\text {ns }}: \mathrm{p}>0.05 ;{ }^{\mathrm{c}}: \mathrm{p}<0.01 ;{ }^{\mathrm{b}}: \mathrm{p}<0.01 \&^{\mathrm{a}}: \mathrm{p}<0.001$ (Std: Standard Glybinclamide treated group \& SSPC5, SSPC8, SSPC11, SSPC14, SSPC15 treated groups of animals were compared to Diabetic control group of animals at different time intervals

* The difference was considered significant when $p$ value $<0.05$.

* Comparison of Mean\% Reduction of Blood Glucose Level (Table 4) after administration of Standard Drug (Glibenclamide) and Test Drug via oral Route (Figure 4).

\section{Cardiomyopathy activity}

The diabetic cardiomyopathy activity of the synthesized test drug SSPC14 was done on Alloxan induced diabetic rats by recording the electrocardiogram of both diabetic and control rat and are shown below.

The ECG recording for normal control and diabetic control group were done in an interval of two hour for two days.

The ECG recording for treatment group was done contentiously six hours after drug treatment and then an interval of six hour up to the 54 hours (Figures 5 and 6).

After giving the treatment drug SSPC 14 the rat's heart rate appeared to normalize in $15 \mathrm{~min}$ and completely normalized in one hour. The heart rate is normal up to the $54 \mathrm{hr}$. after the drug treatment.

\section{The HRV Analysis}

The HRV analysis was difficult. HRV spectrum analysis suggests no variation in the sympathetic and parasympathetic systems related to cardiac system.

\section{There is Elevation in the S-T Segment}

The ST segment represents the period when the ventricles are depolarized.

Average S-T prolongation for normal healthy rats was $34.8 \mathrm{sec}$.

Average S-T prolongation for diabetic rats was $44.6 \mathrm{sec}$. $54 \mathrm{hr}$.

Average S-T prolongation for drug treatment rats was $32.6 \mathrm{sec}$ after

\section{ECG Power Spectrum Analysis}

The overall power of ECG frequency spectra was increased just after the oral dose of compound (SSPC14) and it was sustained till lhour, then started deteriorating.

\section{QRS Interval Analysis}

QRS interval of drug treated diabetic rats was longer (expanded) that is duration was increased.

QRS interval for control (normal healthy rats) is $17.6 \mathrm{msec}$.

QRS interval for control diabetic rat is $25.0 \mathrm{msec}$.

The above docking studies, ADME studies, antidiabetic studies show that compounds SSPC5, SSPC8, SSPC11, SSPC14 and SSPC15 show significant decrease in the blood glucose levels. The cardiomyopathic study with SSPC14 show significant activity on the heart and also brings the ECG to almost normal after 54 hrs (Figures 7-12).

\section{Result and Discussion}

\section{Designing}

Among the 20 hybrid compounds designed using GLIDE

\section{Group}

I (Normal control)

II(Diabetic control)

III(Standard drug)

IV(Test drug SSPC0)

$\mathrm{V}$ (Test drug SSPC5)

VI (Test drug SSPC8)

VII(Test drug (SSPC11)

IX (Test drug SSPC15)
VIII(Test drug SSPC14)

\author{
Treatment After Attainment Of Hyperglycemia \\ Received saline water \\ No treatment \\ Received Standard glibenclamide $2 \mathrm{mg} / \mathrm{kg}$ b.w. Orally \\ Received Cinnamic acid(50 mg/kg b.w.) Orally. \\ Received SSPC5 (50 mg/kg b.w.) Orally. \\ Received SSPC8 (50 mg/kg b.w.) Orally. \\ Received SSPC11 (50 mg/kg b.w.) Orally. \\ Received SSPC14 (50 mg/kg b.w.) Orally. \\ Received SSPC15 (50 mg/kg b.w.) Orally.
}

Table 3: Group of animals treated with different test drug.

\begin{tabular}{|c|c|c|c|c|c|c|}
\hline TIME (in hr.) & 0 & 2 & 4 & 6 & 12 & 24 \\
\hline Normal Control & $87.25 \pm 1.051^{a}$ & $90.38 \pm 0.8625^{a}$ & $88.00 \pm 1.071^{a}$ & $104.2 \pm 0.7984^{a}$ & $98.28 \pm 0.8625^{a}$ & $112.3 \pm 1.018^{\mathrm{a}}$ \\
\hline Diabetic Control & $232.55 \pm 1.041^{a}$ & $257.5 \pm 1.047^{\mathrm{a}}$ & $252.1 \pm 0.7969^{a}$ & $293.1 \pm 0.7561^{a}$ & $215.3 \pm 25.60^{a}$ & $257.6 \pm 1.085^{\mathrm{a}}$ \\
\hline Standard & $228.4 \pm 1.008^{a}$ & $168.3 \pm 0.8627^{\mathrm{a}}$ & $116.6 \pm 1.258^{a}$ & $92.58 \pm 0.7846^{a}$ & $187.2 \pm 1.017^{\mathrm{a}}$ & $218.2 \pm 0.8391^{a}$ \\
\hline SSPCO(cinnamic acid) & $277.8 \pm 0.9810^{\mathrm{a}}$ & $212.6 \pm 1.031^{b}$ & $198.1 \pm 0.778^{a}$ & $180.6 \pm 0.9242^{\mathrm{a}}$ & $154.2 \pm 0.2721^{b}$ & $213.1 \pm 1.121^{a}$ \\
\hline SSPC5 & $261.3 \pm 1.514^{a}$ & $212.6 \pm 1.077^{b}$ & $130.2 \pm 0.9013^{a}$ & $89.72 \pm 0.7217^{a}$ & $154.5 \pm 2.136^{b}$ & $166.2 \pm 1.485^{\mathrm{a}}$ \\
\hline SSPC8 & $256.8 \pm 1.228^{a}$ & $178.0 \pm 1.006^{a}$ & $165.6 \pm 0.8330^{a}$ & $127.4 \pm 1.030^{\mathrm{a}}$ & $163.0 \pm 9.054^{\mathrm{a}}$ & $232.5 \pm 0.9003^{a}$ \\
\hline SSPC11 & $242.2 \pm 1.258^{a}$ & $194.6 \pm 1.512^{\mathrm{a}}$ & $165.9 \pm 0.4761^{a}$ & $177.7 \pm 1.047^{\mathrm{a}}$ & $224.4 \pm 0.8587^{a}$ & $209.9 \pm 1.093^{a}$ \\
\hline SSPC14 & $262.5 \pm 1.041^{a}$ & $237.8 \pm 25.93^{\text {ns }}$ & $107.2 \pm 1.050^{\mathrm{a}}$ & $112.5 \pm 1.021^{\mathrm{a}}$ & $166.3 \pm 1.328^{a}$ & $222.5 \pm 1.310^{\mathrm{a}}$ \\
\hline SSPC15 & $239.7 \pm 1.041^{\mathrm{a}}$ & $240.1 \pm 2.042^{\text {ns }}$ & $187.9 \pm 0.9836^{a}$ & $160.1 \pm 0.8784^{a}$ & $213.9 \pm 0.8481^{a}$ & $234.0 \pm 1.374^{a}$ \\
\hline
\end{tabular}

Table 4: Comparision of Mean Glucose Level. 


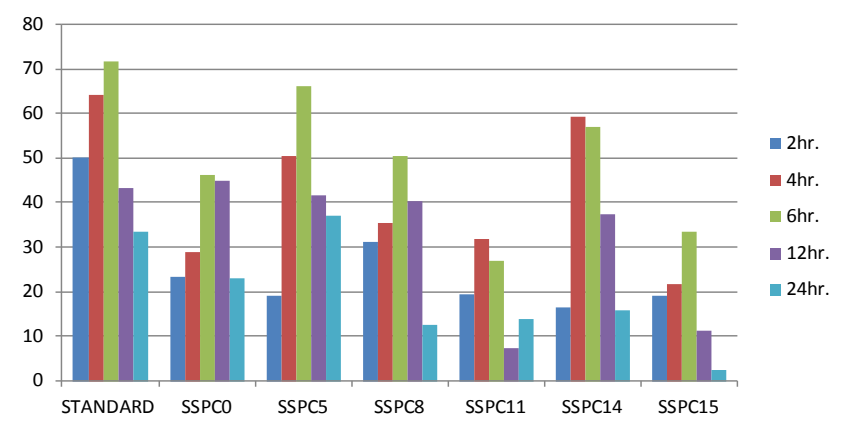

Figure 4: Bar Chart Representing Comparison of Mean \% Reduction of Blood Glucose Level after administration of Standard Drug Glibenclamide, and Test Drug via oral Route.

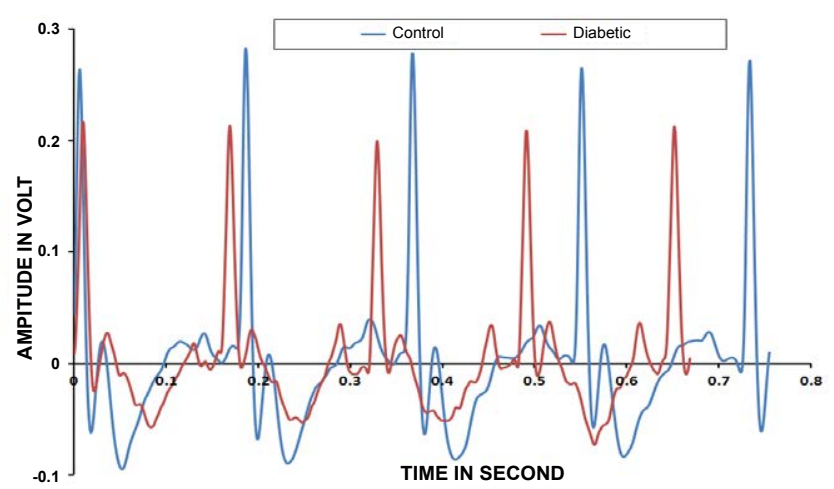

Figure 5: Sample ECG of 'Control' and 'Diabetic' rats.

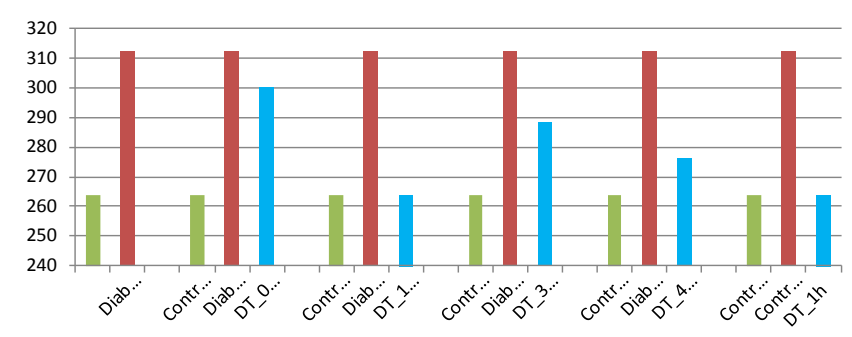

Figure 6: Heart ratevariation control, diabetic and drug treated animal.

\section{Control}

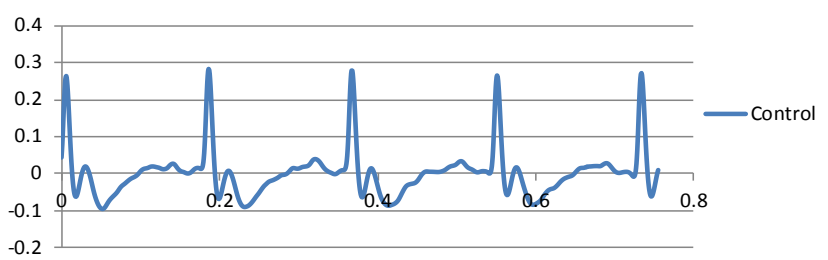

Figure 7: Sample ECG of 'control' rats.

DOCKING software using various amino acids SSPC5, SSPC8, SSPC11, SSPC14, SSPC15 having Phenylalanine, Proline, Glycine Cysteine, and Tyrosine respectively showed good docking scores of -12.89,-12.47,6.16,-8.66,-12.37 with the AMPK (PDB ID: 2Y94) and -8.47,-10.08, $-6.29,-8.39,-7.39$ with PPAR $\gamma$ (PDB ID: 3ET0) receptor.

Good binding can be seen for the above compounds with amino- acid residues GLN286, TYR473, SER289, HIS449, LEU330SER289, TYR327, HIS449, TYR473 of PPAR $\gamma$ receptor also through H-bonding.

SSPC14 showed almost similar scores of -8.66 and -8.39 in AMPK and PPAR $\gamma$ receptor, respectively, so it was selected for both antidiabetic and diabetic cardiomyopathic study. ADME studies showed Human oral absorption of 3 (good) for SSPC5, SSPC8, SSPC11, SSPC14 and (medium) for SSPC15. Their \% Oral Absorption being 85.34, 81.14, $69.57,78.70$ and 71.38 , respectively which is also significant.

\section{Synthesis}

The hybrid compounds having Cinnamic acid in combination

Diabetic

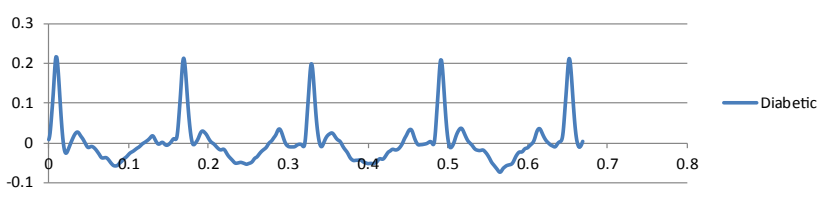

Figure 8: DOCKING Sample ECG of 'Diabetic' rats.

DT $15 \mathrm{~min}$

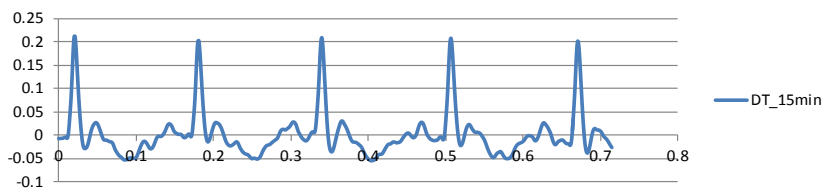

Figure 9: ECG of 'Diabetic treatment' rats after $15 \mathrm{~min}$.

DT_1h

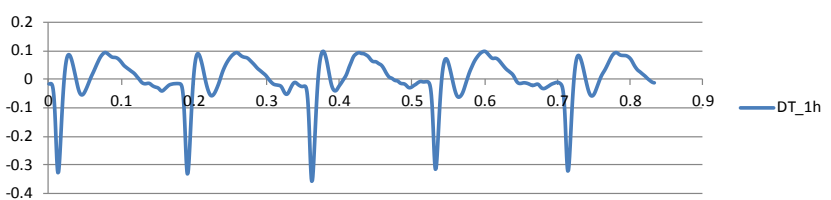

Figure 10: ECG of 'Diabetic treatment' rats after $1 \mathrm{hr}$.

DT 2D

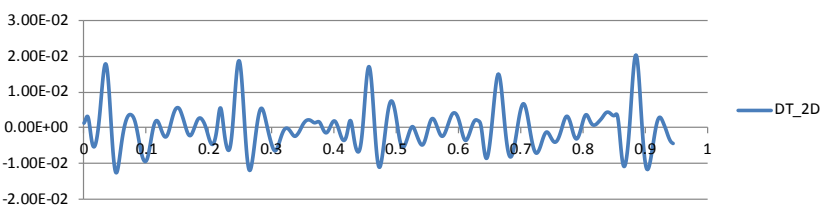

Figure 11: ECG of 'Diabetic treatment' rats after $48 \mathrm{hr}$.

DT_2D6h

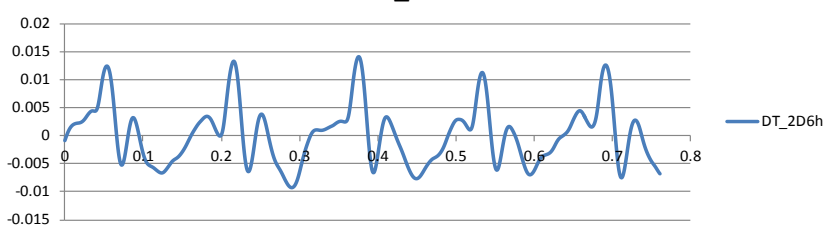

Figure 12: ECG of 'Diabetic treatment' rats after $54 \mathrm{hr}$. 
with the amino acids (Phenylalanine, Proline, Glycine Cysteine, and Tyrosine) were synthesized using liquid phase method with chlorophosphate ester as the condensing reagent. Yield of these were about $80 \%$ and showed good crystalline nature. The physicochemical properties like melting point, Rf value and Spectral studies like FT-IR, NMR and Mass used for characterization of all synthesized compounds and confirmation of the same.

\section{Pharmacological screening}

Anti-diabetic studies of SSPC5, SSPC8, SSPC11, SSPC14, SSPC15, and SSDM-12 on Alloxan induced rats by tail vein puncture method, showed significant decrease in the blood glucose level at 2, 4, 6, 12, and 24 hours. Cinnamic acid has a proven ant diabetic activity. SSPC5, SSPC8, SSPC11, SSPC14 showed \% reduction in blood glucose of $37.02 \%, 12.5,14.04,15.96 \%$ and $2.51 \%$ as compared to standard with $33.53 \%$ reduction.

The compound SSPC14 was subjected to Diabetic cardiomyopathy activity, induced in rats after 14 days of alloxan treatment was found to be very effective at the given dose and has a prolong duration of action on the heart (Up to $54 \mathrm{hrs}$.). ECG pattern was normal for first $15 \mathrm{mins}$ but a very distinct inversion was observed in the ECG pattern from $30 \mathrm{mins}$ to $24 \mathrm{hrs}$ after administration of drug which started normalizing after $30 \mathrm{hrs}$ till $54 \mathrm{hrs}$ of the study. The heart rate was normal up to $54 \mathrm{hr}$. after the drug treatment.

\section{Conclusion}

Thus we conclude that this approach is a new innovative idea to design, synthesise and screen for the antidiabetic and cardiomyopathic activities of cinnamic acid-amino acid hybrid analogues which has given a new direction for the establishment of newer compounds which would be beneficial for both diabetes and cardiomyopathy and help to retain normal cardiac function. The use of non-invasive cardiomyopathic animal screening is a new model in addition to the conventional pharmacological screening.

\section{Acknowledgment}

We deeply acknowledge Vice-Chancellor, BIT Mesra and Head of Department, Pharmaceutical Sciences, Department of Biomedical Instrumentation, and other departments for supporting us with all the facilities within the Institute.

\section{References}

1. King H, Aubert RE, Herman WH (1998) Global burden of diabetes, 1995-2025 prevalence, numerical estimates, and projections. Diabetes Care 21: 14141431.

2. Definition and diagnosis of diabetes mellitus and intermediate hyperglycemia, Report of a WHO/IDF Consultation (2006) World Health organization.

3. Rubler S, Dlugash J, Yuceoglu YZ, Kumral T, Branwood AW, et al. (1972) New type of cardiomyopathy associated with diabetic glomerulosclerosis. Am J Cardiol 30: 595-602.

4. Factor SM, Bhan R, Minase T, Wolinsky H, Sonnenblick EH (1981) Hypertensive-diabetic cardiomyopathy in the rat: an experimental model of human disease. Am J Pathol 102: 219-228.

5. Dike Bevis Ojji (2011) Diabetic Cardiomyopathy. Intech 978-953-307-597-6,

6. Lee EJ, Kim SR, Kim J, Kim YC (2002) Hepatoprotective phenylpropanoids from Scrophularia buergeriana roots against $\mathrm{CCl} 4$-induced toxicity: Action mechanism and structure-activity relationship. Planta Med 68: 407-411.

7. Liu IM, Hsu FL, Chen CF, Cheng JT (2000) Antihyperglycemic action of isoferulic acid in streptozotocin-induced diabetic rats. $\mathrm{Br} \mathrm{J}$ Pharmacol 129: 631636.

8. Natella F, Nardini M, Di Felice M, Scaccini C (1999) Benzoic and cinnamic acid derivatives as antioxidants: structure-activity relation. J Agric Food Chem 47: 1453-1459.

9. Di Carli MF, Bianco-Batlles D, Landa ME, Kazmers A, Groehn H, et al. (1999) Effects of autonomic neuropathy on coronary blood flow in patients with diabetes mellitus. Circulation 100: 813-819.

10. Ghosh R, Thanawala V, Kadam JV ( 2007) Novel Peptides: An Alternative Approach for the Treatment of Diabetes Mellitus, Current Drug Therapy 3: 196204.

11. Eun-Do Kim, Jung-HL, Chang-KH (2011) Gly-Ala-Gly-Val-Gly-Tyr, a novel synthetic peptide, improves glucose transport and exerts beneficial lipid metabolic effects in 3T3-L1 adipoctyes. Eur J Pharmacol 650: 487-708. 